\title{
NOTAS SOBRE ANÁLISES DE RISCOS E GESTÃO DE SEGURANÇA EM UMA ORGANIZAÇÃO HOSPITALAR: ESTUDO DE CASO EM UM MUNICÍPIO DO RIO DE JANEIRO
}

\author{
P.C.Hamada ${ }^{1}$; G.S.Assumpção $^{1}$; C.T.P.Lopes ${ }^{1}$; D.Costa ${ }^{1}$; G.F.F.Pereira ${ }^{1}$; N.E.Silva ${ }^{1}$; A.C.Castro ${ }^{1}$
}

1 Centro Federal de Educação Tecnológica Celso Suckow da Fonseca, 20271-110, Rio de Janeiro-RJ, Brasil

*pchamada@yahoo.com.br

Artigo submetido em 04/10/2015 e aceito em 01/02/2016

\section{RESUMO}

Este estudo teve como objetivo analisar os processos de gestão de segurança em um hospital de um grande município no Estado do Rio de Janeiro. O método de pesquisa empregado foi o estudo de caso, estratégia escolhida por incluir tanto observação direta, quanto uma série de entrevistas. Os resultados obtidos permitiram destacar a importância da gestão de segurança em um hospital para que sejam possíveis ações que visem conscientizar os funcionários, avaliar os cenários de riscos e controlar os fluxos logísticos de pacientes, produtos e resíduos contaminados.

\section{NOTES ON RISKS ANALYSIS AND SECURITY MANAGEMENT IN A HOSPITAL ORGANIZATION: A CASE STUDY IN A CITY OF RIO DE JANEIRO}

\begin{abstract}
This study aimed to analyze the processes of security management in a hospital in a big city at Rio de Janeiro's State. The research method used was case study, strategy chosen by include both direct observation as a series of
\end{abstract}

interviews. The obtained results allowed to highlight the importance of security management in a hospital, educate employees, assess risk scenarios, control the logistics flows of patients and contaminated products and waste.

KEYWORDS: Risk management, Security management, Hospital organization. 


\section{INTRODUÇÃO}

Com a crescente exigência do mercado pela excelência na qualidade da prestação dos serviços, empresas de todos os ramos têm buscado, de forma consistente, o aprimoramento e a inovação nas suas formas de gestão. Essa busca pela qualidade é latente no campo da gestão da saúde, pois as empresas desse ramo também tendem a perceber que a assistência pura e simples, não pode ser concebida à parte de uma complexa gama de demandas. Assim, é preciso, do ponto de vista da administração, que haja uma efetiva qualidade na prestação da assistência hospitalar.

Nesse sentido, para que as empresas e organizações que prestam serviços de saúde possam atingir dado padrão de qualidade, faz-se mister que suas gestões sejam orientadas para disponibilizar formas de atendimento e assistências seguras e eficazes, com procedimentos qualificados na prestação desses serviços. Consequentemente, torna-se necessário superar a imagem dos hospitais, construída há séculos, como uma simples organização relacionada à caridade e atendimento misericordioso a desassistidos. De fato, para além dessa visão mistificadora, a tendência atual na Gestão da Saúde é a de ver o hospital sob o prisma organizacional e, portanto, suscetível a processos administrativos preconizados pelas atuais tendências e teorias de Management (ERDTMANN, 2004). Sem que isso implique, é claro, fugir à essência de empresa prestadora de serviços de saúde à sociedade, pois a visão assistencial de um hospital deve justamente primar pelos cuidados voltados ao reestabelecimento da saúde do paciente internado (COSTA E GRECO, 2011).

Uma análise bibliográfica de estudos sobre a estrutura organizacional dos estabelecimentos assistenciais de saúde permite verificar que, nos últimos anos, a incorporação de procedimentos sistematizados de gestão tem melhorado em muito as rotinas de trabalho anteriores, principalmente no escopo da segurança e da redução dos riscos de acidentes no ambiente de trabalho (BRITO, 2001), aqui entendidos como combinação tanto da probabilidade de ocorrência quanto da severidade do dano. Avanços esses que ocorrem concomitantemente ao incremento de ações do Ministério da Saúde, por meio da Agência Nacional de Vigilância Sanitária (ANVISA), que desde os anos 1990 tem ampliado a fiscalização e desenvolvido normas de vigilância sanitária nos hospitais a fim de garantir a segurança dos atendimentos prestados (AZEVEDO NETO, 2004).

Esse atual cenário suscitou o interesse desta investigação, pois os desenvolvimentos no campo da Gestão de Saúde e Segurança podem ser observados tanto no dia-a-dia de hospitais e clínicas, quanto no aumento de artigos publicados sobre o tema (RIGOBELLO ET AL, 2012). Dessa forma, no âmbito dos estudos sobre segurança do trabalho, foi desenvolvido um projeto de pesquisa cujo objetivo foi, na forma de um estudo de caso, analisar os processos de gestão de segurança em um dado hospital no Rio de Janeiro.

A escolha do hospital que serviria de base à pesquisa atendeu a critérios de viabilidade e relevância definidos pelo grupo de trabalho que empreendeu a investigação. Isso porque trata-se de um hospital de grande porte (LIMA ET AL., 2004), em um grande município do Estado do Rio de Janeiro. A caracterização dessa instituição hospitalar, apresentada a seguir, decorre de documentos institucionais que, no entanto, não serão aludidos no referencial bibliográfico, por conta da confidencialidade exigida. Referências e nomes de entrevistados que permitiriam a identificação da instituição serão omitidas.

Buscou-se o estabelecimento de uma relação de confiança, em que foi assegurado aos participantes um mecanismo de proteção através do anonimato. Dessa forma, embora alguns pesquisadores no campo da gestão considerem que o caráter da pesquisa é incompatível com o segredo implícito na confidencialidade (SPINK E MENEGON, 2004), esse foi o compromisso ético da pesquisa. 
O hospital tomado como objeto deste artigo possui uma localização privilegiada, o que possibilita acesso fácil não só de pessoas do mesmo município, como também de moradores de outros municípios próximos e até da capital do Rio de Janeiro. Segundo informado, a construção do hospital foi cuidadosamente planejada para que cada espaço fosse aproveitado ao máximo, oferecendo conforto e segurança aos pacientes e funcionários.

A construção de um hospital desse porte é de grande relevância tanto para o município onde está localizado quanto para o Estado do Rio de Janeiro. Pela Pesquisa de Assistência MédicoSanitária (AMS) de 2009 (IBGE, 2010), pode-se ver que os estabelecimentos com internação diminuíram seu número, devido à desativação de estabelecimentos privados com internação. Essa tendência de redução ocorre desde 1999. Em todo o país, o setor privado perdeu 392 estabelecimentos, entre 2005 a 2009. No setor público, houve aumento de 112 estabelecimentos. Mas isso não impediu a concretização de um déficit de 280 estabelecimentos com internação para o período. É possível observar, ainda através dos dados da AMS 2009, que a taxa de leitos por 1.000 habitantes também sofreu redução, caindo de 2,4 para 2,3 leitos por 1.000 habitantes. Somente a Região Sul, com 2,6 leitos por 1.000 habitantes, atingiu valores deste indicador dentro do parâmetro preconizado pelo Ministério da Saúde, estipulado entre 2,5 e 3 leitos por 1.000 habitantes.

Quanto à capacidade instalada, atualmente o hospital conta com um elevado número de leitos (cerca de 250 leitos), inclusive com UTI (Unidade de Tratamento ou Terapia Intensiva), incluindo um leito para pacientes em isolamento respiratório, e um elevador exclusivo para o deslocamento de pacientes graves diretamente ao centro cirúrgico e ao CTI (Centro de Terapia Intensiva). A documentação examinada indica uma estrutura muito bem preparada para atender casos de emergência, tanto de adultos quanto de crianças, mediante a metodologia chamada de "Smart Track", onde a gestão do fluxo de pacientes ajuda a diminuir o tempo de espera pelo atendimento.

O Centro de Terapia Intensiva (CTI), aliás, especialmente projetado para assegurar o isolamento tanto físico quanto respiratório de pacientes com infecções contagiosas, permite um eficiente controle microbiológico. $\mathrm{O}$ amplo centro cirúrgico conta com salas de cirurgia equipadas com a técnica do fluxo laminar, uma barreira que permite o combate às infecções hospitalares. Há também uma ala destinada à Central de Material Esterilizado, com amplo espaço, rigorosamente ajustada às normas sanitárias vigentes (MINISTÉRIO DA SAÚDE, 2001).

Todos os quartos são equipados com leito inteiramente automatizado e banheiros privativos que oferecem o máximo de segurança aos pacientes. Visando oferecer o máximo de conforto possível, estão disponíveis também em cada quarto TV LCD, frigobar, telefone, ar-condicionado e sofá-cama para os visitantes ou acompanhantes. Além da estrutura interna de cada quarto, foi possível constatar que o hospital disponibiliza uma ampla área com lounge, cafeteria e capela ecumênica para os visitantes e familiares de pacientes internados.

No que diz respeito aos recursos humanos, o hospital possui uma equipe multidisciplinar de saúde (com enfermeiros, psicólogos, nutricionistas e médicos) e um corpo clínico qualificado nas seguintes especialidades: pediatria, geriatria, urologia, ortopedia, radiologia, oncologia, cirurgia de cabeça e pescoço, cardiologia, cirurgia vascular, cirurgia torácica, neurologia, neurocirurgia, ginecologia, cirurgia plástica, infectologia, endoscopia digestiva e de vias biliares. 
Todo o cenário aqui descrito permite evidenciar a relevância e pertinência deste artigo, pois a investigação empreendida teve por foco uma organização hospitalar de destaque, em termos de infraestrutura e recursos humanos, no âmbito dos hospitais da rede privada do estado do Rio de Janeiro, e pode contribuir com outros estudos na área.

\section{MATERIAIS E MÉTODOS}

A metodologia empregada nesse estudo, realizado entre setembro e novembro de 2014 , foi qualitativa, através de procedimentos imbricados no estudo de caso. Esse método, o estudo de caso, caracteriza-se na literatura acadêmica como uma forma de se investigar uma organização seguindose um conjunto de procedimentos pré-especificados, mormente a observação direta e a série sistêmica de entrevistas (MENEZES, 2009).

Em um primeiro momento foram feitos acertos de campo. O contato inicial com a direção do hospital implicou esclarecimentos e consentimentos em função da confidencialidade, já referida. Assim, somente em face desses acertos, foram agendadas entrevistas semiestruturadas com profissionais responsáveis pela segurança do trabalho no hospital, para que a coleta de informações pudesse ser realizada.

Tais entrevistas, contudo, foram precedidas por visitas e observações, a fim de se conhecer, acompanhar e investigar as práticas e métodos utilizados no local de trabalho. Nessa etapa da pesquisa, os pesquisadores estiveram no hospital e foram conduzidos à área dos técnicos de segurança, onde foram coletados documentos e procedimentos-padrão que normatizam a segurança do trabalho no hospital. Posteriormente, a fim de analisar fatores de risco presentes na organização hospitalar (como, por exemplo, proliferação dos agentes patogênicos, incêndio, contaminação da comida, descarte de material contaminado e possibilidade de acidentes de trabalho), os pesquisadores se dirigiram para o local de triagem (onde é realizada a primeira etapa do atendimento às pessoas que dão entrada no hospital), setor em que, nesse hospital, se situa a gestão de segurança da instituição. A ideia era a entender a rotina de trabalho e as práticas adotadas dentro do hospital para minimizar e reduzir riscos e acidentes.

$\mathrm{Na}$ área da saúde, o conceito de risco se refere à probabilidade de ocorrência de um evento mórbido ou fatal, e está centrado tanto na discussão em torno de ações preceptivas que ocorrem a partir da identificação de exposição a fatores de risco, quanto nas ações de controle e segurança dirigidas aos riscos ocupacionais. Há vasta bibliografia sobre riscos e gestão de segurança em hospitais (ERDTMANN, 2004), e o próprio hospital estudado disponibilizou material produzido internamente a esse respeito. Grande parte dos resultados apresentados e discutidos no próximo tópico, entretanto, decorre das entrevistas semiestruturadas, caracterizadas pelo uso de um roteiro previamente elaborado. Tal método, especialmente direcionado aos assuntos que configuravam a base da pesquisa, permitiu o desenvolvimento da análise em direção ao objetivo proposto, ou seja, analisar os processos de gestão de segurança do hospital. Assim, foram entrevistados os três técnicos de segurança, a médica responsável pela gestão de segurança, e o gestor de operações do hospital.

Uma vez que nas visitas também foram tiradas fotos (aqui reproduzidas com autorização da instituição) e coletados normas, panfletos informativos e instruções institucionais, a pesquisa também incorporou procedimentos de análise documental. O intuito era ter conhecimento do máximo de informações relevantes para compreensão dos processos de gestão do hospital. O que vale dizer que essa etapa metodológica envolveu mecanismos de seleção, avaliação e interpretação de informações contidas em diferentes documentos, produzidos e elaborados pela própria organização estudada (CARMO E FERREIRA, 1998). 


\section{RESULTADOS E DISCUSSÃO}

Em linhas gerais, o resultado da pesquisa evidenciou que, comparado a ambientes de atividades industriais - mais enfatizados pelos estudos de Gestão de Segurança - o contexto hospitalar apresentou problemas singulares e atípicos, nas múltiplas dinâmicas que afetam pacientes e funcionários, aspecto, aliás, que corroborou resultados de outras investigações sobre o mesmo tema (AZEVEDO NETO, 2004). Assim, conquanto fosse um ambiente orientado primordialmente ao bem-estar das pessoas atendidas, por conta de procedimentos terapêuticos, percebeu-se que a organização hospitalar poderia paradoxalmente apresentar perigos, ameaças, riscos e diversas ocorrências relacionados à segurança.

Institucionalmente, desde que a portaria $\mathrm{n}^{\circ} 5$, de 17 de agosto de 1992 do DNSST (Departamento Nacional de Segurança e Saúde do Trabalhador) do Ministério do Trabalho, criou a obrigatoriedade da construção do Mapa de Risco, foi possível examinar a representação gráfica do reconhecimento dos riscos existentes nos diversos locais do hospital. Sem contestar a validade desses registros para a conscientização dos funcionários, através da fácil visualização dos riscos presentes no cotidiano laboral (MINISTÉRIO DO TRABALHO, 1992), a investigação evitou reduzir-se tão somente à identificação de tais riscos. Por conta disso, buscou problematizar as questões presentes na dinâmica relacional, dando prioridade às falas das pessoas envolvidas nesse processo.

A análise de resultados aqui empreendida não consistiu em mera transcrição das informações coletadas nas entrevistas, tampouco na reprodução descritiva do conteúdo dos documentos. Ao contrário, o que se pretendeu foi realizar uma análise crítica dos dados obtidos durante a realização da pesquisa.

As entrevistas, particularmente, permitiram identificar focos de interesse específico em diferentes responsáveis pelos processos organizacionais. Os técnicos de segurança manifestaram mais preocupação com a conscientização dos funcionários, o que é estritamente uma de suas atribuições. A médica responsável pela segurança, por sua vez, procurou enfatizar que a gestão de segurança trabalha com vários cenários de riscos que o hospital poderia enfrentar, desde contaminações, até catástrofes naturais e incêndios. Já o gestor de operações do hospital concentrou sua análise nas questões que dizem respeito ao aspecto logístico do hospital, efetivamente fundamental para a gestão da segurança e a eficácia das operações.

Assim sendo, diante do objetivo proposto - analisar os processos de gestão de segurança foram destacados e sistematizados os elementos mais preponderantes da organização hospitalar estudada. Indicados a seguir, tais tópicos resultaram das observações in loco, das respostas dadas nas entrevistas, e do conteúdo da documentação examinada.

\subsection{A questão da conscientização dos funcionários}

Quando os funcionários começam na empresa, passam por uma semana de adaptação. Ao contrário de outras empresas com dinâmicas diferentes, a orientação de segurança não é feita em bloco. Os técnicos de segurança do trabalho - que nesse hospital são em número de três — vão às diferentes áreas para mostrar os equipamentos de proteção individual obrigatórios (EPI's), e verificar o andamento das atividades, dirimindo dúvidas e apontando não-conformidades.

Dessa forma, as atividades de conscientização ocorrem rotineiramente, através de diálogos realizados ao decorrer do dia, pois como o hospital tem um número elevado de funcionários, fica praticamente impossível planejar palestras visando grande participação, já que cada funcionário tem 
o seu compromisso de trabalho e horários diversos. O que foi verificado é que os técnicos de segurança transitam pelos setores pré-determinados do hospital e, através do diálogo, entregam panfletos com as instruções de segurança, mostrando conseguintemente todos os cuidados e procedimentos que devem ser tomados para minimizar os acidentes de trabalho.

Esses panfletos informativos são preparados especificamente para a segurança do trabalho em ambiente hospitalar e contêm informações tais como descarte de material contaminado e manuseio de equipamentos para exames. Contudo, as orientações para funcionários - e pacientes - aparecem não só nesses folhetos, mas em cartazes e displays encontrados em vários lugares. De fato, todas as lixeiras do hospital possuem instruções acerca de qual tipo de material ou resíduo pode ser descartado naquela determinada lixeira (conforme figura 1).

O aspecto de relevo nesse cenário é que no contexto hospitalar, além dos acidentes comuns a outros ramos da área de serviços prestados, os profissionais das áreas médica e paramédica, bem como os demais funcionários, são continuamente potenciais alvos de infecções (NAIME, SARTOR E GARCIA, 2004). Por isso, diante da necessidade de controle contínuo, vale ressaltar que o hospital realiza blitz com os funcionários para fiscalizar os procedimentos de segurança, tais como uso de Equipamentos de Proteção Individual (EPIs) por profissionais envolvidos em atividades de risco (luvas, máscaras, óculos e roupas de proteção). Aspecto esse que inclusive analisa se eles estão vestidos adequadamente no local de trabalho, pois não há permissão para uso de pertences como cordões, pulseiras e brincos, pois comprometem a segurança microbiológica.

\subsection{A questão dos acidentes de trabalho}

No caso de um acidente de trabalho, é gerada uma sindicância, ou seja, uma investigação do episódio. O procedimento é minucioso, pois nesse hospital, conforme dado obtido na entrevista, já ocorreram casos de funcionários forjarem acidentes para se beneficiarem com uma possível folga concedida pela licença médica.

As sindicâncias, todavia, são muito úteis para os planejamentos de prevenção, depois de apuradas, interpretadas e tabuladas. A razão disso é que o estudo e investigação dos acidentes são fundamentais para a futura prevenção e conscientização dos funcionários. Dessa forma, tanto é possível evitar os acidentes, quanto minimizar os casos, pois com a apuração das sindicâncias é possível identificar onde ocorre a maioria dos acidentes para, assim, alertar melhor os profissionais que atuam naquela dada área do hospital.

Os acidentes de trabalho, entretanto, podem ser também os de percurso, quando o funcionário sofre o acidente ao se dirigir até o local do trabalho (nesse caso podendo ser tanto um tombo na rua, quanto dentro do ônibus, ou ainda um acidente qualquer de trânsito), como também no trajeto do trabalho para residência. Situações, obviamente, que induzem a noções de sindicância e conscientização distintas daquelas nas quais o sinistro ocorre dentro do local de trabalho.

\subsection{A questão do descarte de material contaminado}

Sob a ótica da gestão de segurança em um hospital, são considerados fundamentais os procedimentos realizados para o descarte e a separação de resíduos biológicos, bem como de lixo hospitalar em geral. Nesse caso, o cuidado maior se dirige para o material contaminado, sendo considerados infectantes os resíduos que constituem graves e mais evidentes riscos para a saúde, pela presença de micro-organismos patogênicos no sangue ou líquidos corpóreos, tais como agulhas, ataduras, bolsas transfusionais com hemocomponentes, cateteres, etc. 
Assim, embora haja uma empresa terceirizada contratada para recolher o material contaminado, o gestor do hospital afirma demonstrar grande preocupação com esse assunto. Sobretudo porque em caso de acidente com o resíduo contaminado, até chegar o momento em que será definitivamente descartado, a responsabilidade é do hospital.

Portanto, dentro do hospital, o descarte do lixo é feito em duas lixeiras distintas: a de Resíduo Comum e a de Resíduo Infectante. Várias normas brasileiras tratam do assunto (NBR 9191, NBR 12809, NBR 13853, NBR 12807, NBR 12808, NBR 11175), mas convém destacar que a NBR 12810 fixa os procedimentos exigíveis para as coletas interna e externa, e a NBR 7500 trata da simbologia para substâncias infectantes. Tais procedimentos foram plenamente constatados (inclusive o uso de recipiente próprio para descarte de material perfuro cortante) e observados dentro do hospital (conforme Figura 1). A empresa terceirizada, no entanto, ao fazer a coleta do material dessas lixeiras, passa a ser a responsável pelo processo de controle dos resíduos para o descarte final.

Figura 1: Lixeira de resíduo comum (à esquerda), e o símbolo de substância infectante preconizado pela NBR 7500 (no centro) sendo utilizado na lixeira de resíduo infectante (à direita).
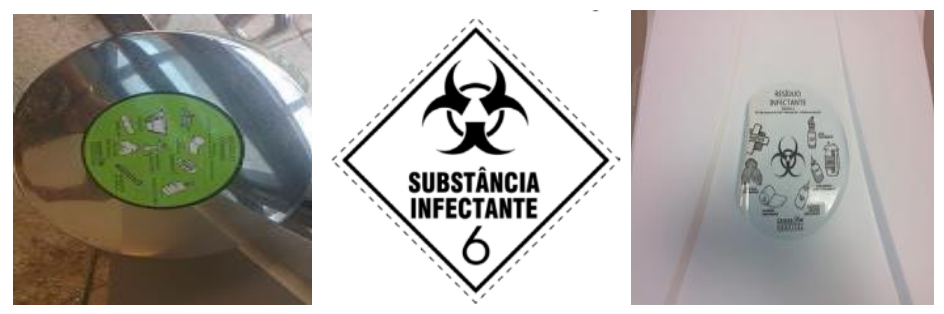

Fonte: Elaborado pelos autores

\subsection{A questão da identificação de risco de um paciente}

Quando um paciente dá entrada no hospital, há um procedimento que envolve componentes de gestão logística para a não proliferação dos agentes patogênicos entre os profissionais e demais pacientes.

Inicialmente, a gravidade é verificada através do processo de triagem, situado no primeiro andar. Há, porém, algumas distinções que segmentam casos graves, de forma a desenvolver procedimentos também diferenciados.

No caso de doenças contagiosas muito raras e específicas - o exemplo citado na entrevista foi o ebola - o paciente é colocado no quarto de isolamento (Figura 2) até que uma equipe de um hospital de referência (trata-se, no Rio de Janeiro, de um hospital público) chegue para removê-lo.

Em se tratando de doenças mais comuns, embora contagiosas - como, por exemplo, uma varicela - o paciente é encaminhado para o quarto de isolamento, que possui um filtro de ar especial, pois o emprego da filtragem de ar para tais ambientes se faz necessário em situações onde é preciso limpar o ar antes de recircular parte do mesmo para o ambiente (BRITO, 2001), de forma a evitar o contágio de doenças pelo ar. E nesse quarto, quando o profissional for realizar o atendimento, deverá estar munido de equipamento de proteção: luva, capote, máscara e estetoscópio específico (as luvas são utilizadas na precaução padrão quando há risco de exposição das mãos a sangue e secreções diversas; o capote é utilizado para qualquer procedimento somente quando o cliente se encontra em precaução de contato, assim como o estetoscópio específico). 
Figura 2: Quarto de isolamento com emprego da filtragem de ar
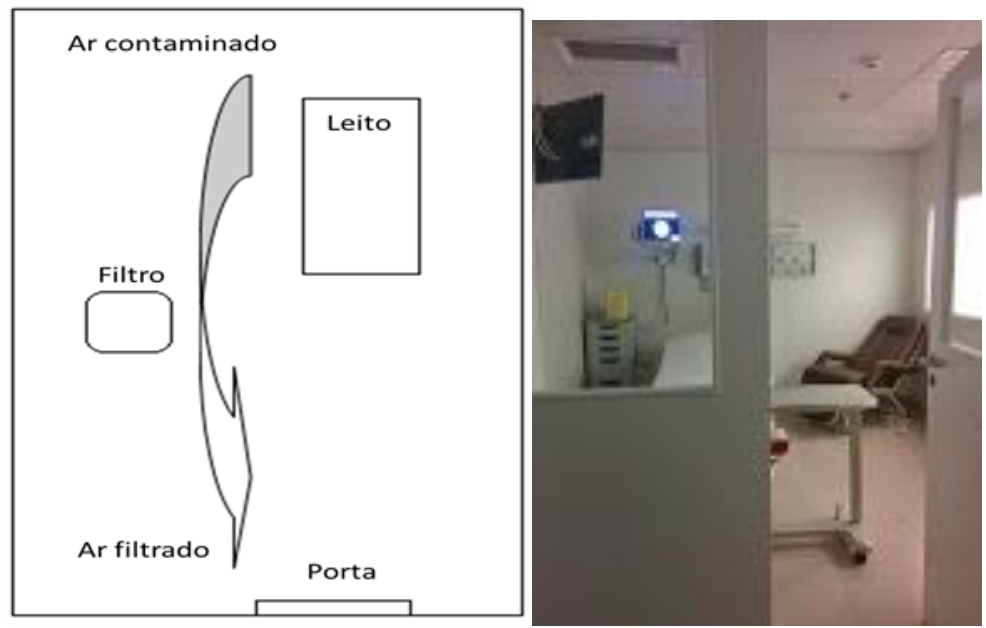

Fonte: Elaborado pelos autores

\subsection{A questão do risco de incêndio}

Dentre os tópicos do plano de segurança, um dos elementos digno de nota é o planejamento contra incêndios, pois, eventualmente, é necessário manuseio de equipamentos e materiais inflamáveis. Por causa disso, o hospital possui sprinklers e sensores manuais que são os dispositivos de segurança indispensáveis nesses casos.

O planejamento de segurança envolve não só o combate inicial ao fogo, mas principalmente um plano de emergência para evasão do local. Nessa contingência, diferentemente do esperado pelo senso comum, o primeiro passo consiste em retirar os pacientes de fácil mobilização, deixando para depois, em um segundo momento, os de mais difícil mobilidade - como os pacientes acamados e/ou ligados a aparelhos - cuja evacuação será procedida com o auxílio da brigada de incêndio do hospital. A evasão dos funcionários e consequente retirada de pacientes é prevista para ser realizada através das duas linhas de escadas anti-fogo, cujas portas são anti-chamas.

\subsection{A questão da relação entre logística e segurança}

No que diz respeito aos aspectos logísticos, cabe ressaltar os procedimentos referentes às refeições, pois a alimentação dos pacientes obedece a normatizações rígidas. A nutricionista do hospital participa da elaboração das refeições, definindo o cardápio. À copeira cabe a tarefa de levar a refeição que será efetivamente entregue ao paciente pelo setor de enfermagem. Essa segurança envolve controles que evitam a contaminação da comida e obrigam o uso de vestimenta adequada por parte do funcionário que entrega a refeição, no caso de pacientes com doenças contagiosas.

Medidas de segurança também são aplicadas ao controle dos remédios, cuja logística procura evitar a contaminação dos medicamentos e ocasionais erros e equívocos na posologia ou dosagem. Pois como os leitos são individuais e, ao lado deles, há uma espécie de armário específico, os medicamentos são colocados nele de maneira fracionada. $\mathrm{O}$ exemplo dado na entrevista foi que se o paciente precisa de apenas um comprimido de Omeprazol por dia, será depositado apenas esse comprimido, e não a caixa, impossibilitando erros no uso do remédio ou ainda lapsos nas aplicações. 
No entanto, além da alimentação e medicação, também os fluxos de pacientes, de materiais e de lixo de um hospital, em especial, precisam ser muito bem controlados. Nada do que está sujo ou contaminado pode cruzar o mesmo caminho do que está limpo. A Figura 3 procura mostrar, de forma esquemática, como funcionam esses fluxos no hospital estudado.

Figura 3: Fluxo de pacientes, materiais e lixo do hospital.

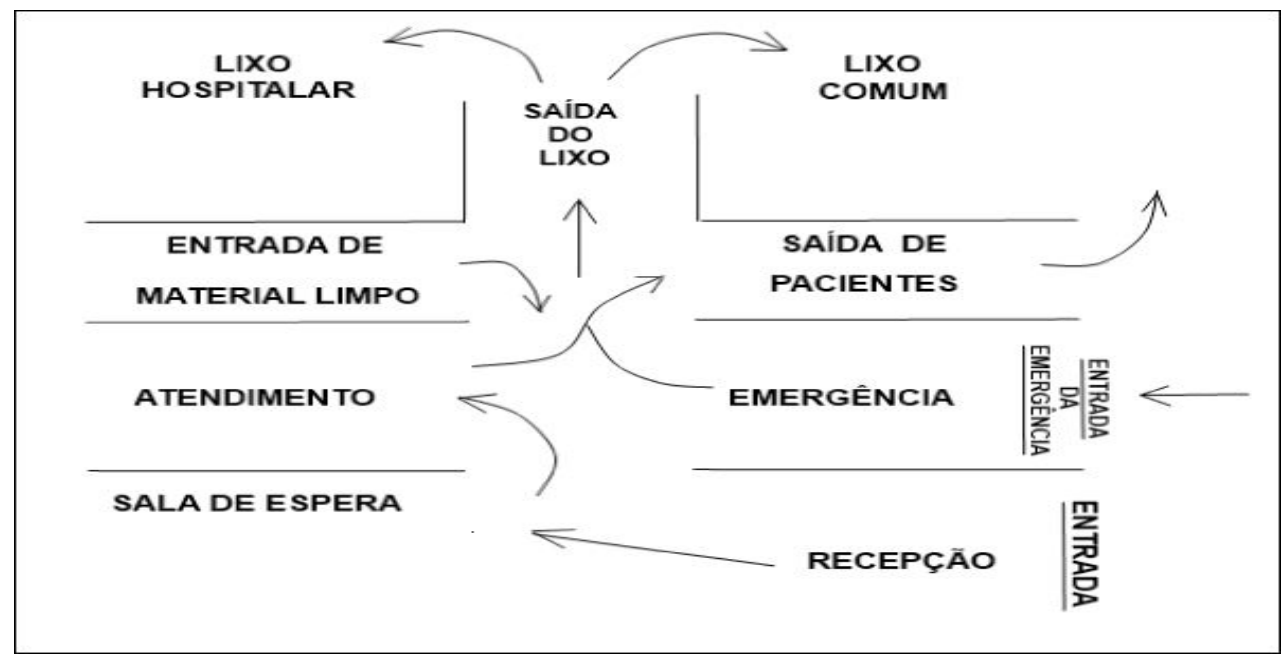

Fonte: Elaborado pelos autores

O material que está esterilizado, mas será empregado no atendimento, entra através das áreas de emergência e atendimento e, após ser utilizado, sai para uma área externa, onde permanecerá separado do lixo comum, em lixeiras próprias, conforme já explicado. Assim, o descarte do lixo que já tinha sido feito, desde o início, em lixeiras apropriadas, aguarda também em lugar próprio a retirada final, pois desse local, indicado na figura 3, serão retirados - o lixo comum e o hospitalar por uma empresa terceirizada pelo hospital para o correto despejo.

Já para os pacientes, há duas entradas: uma para os casos de alto risco de contaminação e outra para os doentes que não apresentam, de antemão, tal risco. O que se verificou na análise realizada na triagem é que os pacientes com doenças contagiosas não cruzam com os outros pacientes nos corredores ou sala de espera, há paredes de separação entre cada corredor distinto, embora haja uma saída comum para todos os pacientes que recebem alta.

Com tal gestão logística, evidente nessa organização, dos fluxos de pessoas e materiais, procura-se evitar qualquer tipo de contaminação, oriunda tanto do contato com o material infectado e/ou o lixo, quanto da relação com portadores de doenças infectocontagiosas. Como a arquitetura do hospital foi planejada especialmente para esse fim, não se tratando de prédio adaptado, toda a organização e estrutura remetem à relação entre logística e segurança, a fim de que os fluxos funcionem de forma otimizada.

\section{CONSIDERAÇÕES FINAIS}

A segurança no trabalho faz parte do dia a dia de muitas organizações. E esta pesquisa verificou que tal cuidado também acontece de forma relevante na organização hospitalar estudada, fato que convida a superar a visão oriunda do senso comum que muitas vezes concebe como foco exclusivo da Gestão da Segurança o ambiente industrial. Segundo essa ótica antiquada, o hospital, contemplado sob viés assistencialista, estaria, por isso, isento de ter esse tipo de preocupação como prioridade. 
A atual situação das organizações hospitalares, que primam pela moderna gestão de serviços, mostra, contudo, que essa imagem ingênua e romântica deve ficar relegada ao passado. Essas empresas também são objeto de fiscalizações, aliás frequentes, da ANVISA e do Ministério do Trabalho. Nessas vistorias, feitas no local, o hospital pode inclusive sofrer sanções, como multas ou interdições, caso sejam identificados desvios ou quaisquer irregularidades.

O hospital estudado, particularmente, possui uma preocupação muito grande com a segurança no trabalho e, por isso, é bem rigoroso no controle de processos e atento às ações de seus funcionários, assim como aos itens utilizados e/ou descartados. Há até, como salientado, procedimentos adotados (e referidos pelos três técnicos de segurança do trabalho como "blitz") com os funcionários para fiscalizar os procedimentos de segurança, se produtos estão dentro da validade e se o descarte está sendo efetuado de maneira adequada.

Diante do objetivo de analisar os processos de gestão de segurança, o ponto a ser ressaltado com maior ênfase nesse estudo de caso é o fato de que critérios de segurança ensejam, necessariamente, sucessivos mecanismos de segmentação. De fato, a análise dos dados coletados mostrou que a necessidade de controle dos riscos resultava na diferenciação entre distintos níveis de prioridades.

O controle de riscos presentes na disseminação de doenças, por exemplo, implica separar pacientes portadores de doenças infectocontagiosas dos demais. Mas também a separar o ar contaminado do filtrado, e o resíduo infectante do comum. E o plano de segurança frente a um cenário de incêndio, por sua vez, se baseia na discriminação entre pacientes segundo o grau de mobilidade. Entretanto, não apenas os pacientes, funcionários, resíduos e materiais passam por processos de clivagem. O próprio espaço físico é da mesma forma compartimentalizado em seus fluxos logísticos e idas e vindas processuais. Tais procedimentos são o fator precípuo da segurança e da preservação da saúde e integridade dos pacientes e funcionários no hospital.

\section{REFERÊNCIAS}

ASSOCIAÇÃO BRASILEIRA DE NORMAS TÉCNICAS. NBR 7500: Símbolos de Risco e Manuseio para o Transporte e Armazenamento de Materiais: Simbologia. Rio de Janeiro, 1994

ASSOCIAÇÃO BRASILEIRA DE NORMAS TÉCNICAS. NBR 9191: Sacos Plásticos para Acondicionamento de lixo: Requisitos e métodos de ensaio. Rio de Janeiro, 2002.

ASSOCIAÇÃO BRASILEIRA DE NORMAS TÉCNICAS. NBR 11175: Incineração de resíduos perigosos. Padrões de desempenho. Rio de Janeiro, 1990.

ASSOCIAÇÃO BRASILEIRA DE NORMAS TÉCNICAS. NBR 12807: Resíduos de Serviços de Saúde: Terminologia. Rio de Janeiro, 1993.

ASSOCIAÇÃO BRASILEIRA DE NORMAS TÉCNICAS. NBR 12808: Resíduos de Serviço de saúde: Classificação. Rio de Janeiro, 1993.

ASSOCIAÇÃO BRASILEIRA DE NORMAS TÉCNICAS. NBR 12809: Manuseio de Resíduos de Serviço de Saúde. Rio de Janeiro, 1993.

ASSOCIAÇÃO BRASILEIRA DE NORMAS TÉCNICAS. NBR 12810: Coleta de Resíduos de Serviço de Saúde. Rio de Janeiro, 1993.

ASSOCIAÇÃO BRASILEIRA DE NORMAS TÉCNICAS. NBR 13853: Coletores para Resíduos de Serviço de Saúde Perfurantes e Cortantes: Requisitos e Métodos de Ensaio. Rio de Janeiro, 1997.

AZEVEDO NETO, F.P.A. Desenvolvimento de tecnologia de gestão para ambientes hospitalares; o caso do Instituto Fernandes Figueira - FIOCRUZ. Dissertação de Mestrado Profissional em Ciência e Tecnologia em Saúde. Escola Nacional de Saúde Pública Sergio Arouca: Rio de Janeiro, 2004. 
BRITO, L. Tuberculose nosocomial medidas de controle de engenharia. Bol. Pneumol. Sanit., São Paulo, v.9, n.2, p.33-50, dez. 2001.

CARMO, H.; FERREIRA, M. Metodologia da investigação. Lisboa: Universidade Aberta, 1998.

COSTA, F. M.; GRECO, R. M. Gerenciando riscos em um hospital universitário: desafios e possibilidades a partir de uma experiência setorial. HU Revista, Rio de Janeiro, v.37, p. 217-224, jan. 2011.

ERDTMANN, B. K. Gerenciamento dos resíduos de serviço de saúde: biossegurança e o controle das infecções hospitalares. Texto contexto - enferm., Florianópolis , v. 13, n. spe, p. 86-93, jan. 2004.

IBGE. Estatísticas da saúde: assistência médico-sanitária 2009. Rio de Janeiro, RJ, 2010. 164 p.

LIMA, S. M. L.et al. Caracterização gerencial dos hospitais filantrópicos no Brasil. Cad. Saúde Pública. Rio de Janeiro, v. 20, n. 5, p. 1249-1261, out. 2004.

MENEZES; M.A.A. Do método do caso ao case: a trajetória de uma ferramenta pedagógica. Educação e Pesquisa, São Paulo, v.35, n.1, p. 129-143, jan./abr. 2009.

MINISTÉRIO DA SAÚDE. Orientações Gerais para Central de esterilização. Brasília: Ministério da Saúde, 2001.

MINISTÉRIO DO TRABALHO. PORTARIA DNSST Nº 5, de 17 de agosto de 1992.

NAIME, R.; SARTOR, I.; GARCIA, A. C. Uma abordagem sobre a gestão de resíduos de serviços de saúde. Revista Espaço para a Saúde, Londrina, v. 5, n. 2, p. 17-27, jun. 2004.

RIGOBELlO, M. C. G. et al . Clima de segurança do paciente: percepção dos profissionais de enfermagem. Acta paul. enferm., São Paulo, v. 25, n. 5, p. 728-735, jan. 2012 .

SPINK, M. J. P.; MENEGON, V. M. A Pesquisa como Prática Discursiva. In: SPINK, Mary Jane (ORG). Práticas discursivas e produção de sentidos no cotidiano: Aproximações teóricas e metodológicas. São Paulo: Cortez, 2004. p. 42-70. 